\title{
Faktor yang Berpengaruh terhadap Kesiapan BPK RI Sulawesi Tenggara dalam "E-Audit"
}

\author{
${ }^{1}$ PRAMITA SUKARSO, 2 ALI ROKHMAN, ${ }^{3}$ SLAMET ROSYADI \\ 123) Program Studi Ilmu Administrasi Pascasarjana Universitas Jenderal Soedirman, \\ JI. HR. Bunyamin 708, Grendeng Purwokerto, Jawa Tengah \\ email: ${ }^{1}$ pramitasukarso@gmail.com, 2 alirokhman@unsoed.ac.id, 3 slametrosyadi@unsoed.ac.id
}

\begin{abstract}
One of the bureaucratic reform implementation is the application of electronic government (e-government). This is for the reason that e-government is considered able to actualize the enhanced performance of bureaucracy. Nevertheless, this application of e-government should also be in unison with the readiness of the officers. The purpose of this research is to analyze factor that affecting The Readiness of Auditor on implementing e-audit as well as to analyze The Readiness of Auditor on implementing e-audit. The respondents were all of auditor of The Audit Board of The Republic of Indonesia Representative Office of Southeast Sulawesi as a census research. To analyze factor that affecting The Readiness of Auditor on implementing e-audit and The Readiness of Auditor on implementing e-audit, a multiple linear regression of questionnaires was used. There were found that Auditor have been ready for e-audit implementation simultaneously Compatibility and Ease of Use affects Auditor Readiness.
\end{abstract}

Keywords: e-audit, e-government, readiness

\begin{abstract}
Abstrak. Salah satu upaya penyelenggaraan reformasi birokrasi adalah dengan penerapan e-government. E-government dianggap mampu mewujudkan peningkatan kinerja birokrasi. Namun, penerapan e-government harus disertai dengan kesiapan yang baik dari aparaturnya sendiri. Penelitian ini bertujuan untuk menganalisis faktor yang memengaruhi kesiapan Pemeriksa dan kesiapan Pemeriksa dalam penerapan e-audit serta untuk mengetahui kesiapan Pemeriksa dalam Penerapan e-audit. Responden dalam penelitian ini adalah semua Pemeriksa pada BPK RI Perwakilan Provinsi Sulawesi Tenggara sebagai penelitian sensus. Untuk menganalisis faktor yang memengaruhi kesiapan Pemeriksa dalam penerapan e-audit dan kesiapan Pemeriksa dalam penerapan e-audit, digunakan analisis regresi linier berganda atas kuisioner yang telah dibagikan. Dari hasil analisis data menunjukkan bahwa siap terhadap penerapan e-audit. Kemudian, secara bersama-sama Compatibility dan Ease of Use berpengaruh terhadap kesiapan Pemeriksa dalam penerapan e-audit.
\end{abstract}

Kata kunci: e-audit, e-goverment, kesiapan

\section{Pendahuluan}

Dalam rangka mewujudkan peningkatan kinerja organisasinya, BPK RI mengambil berbagai langkah modernisasi dalam proses kerjanya yaitu dengan penerapan e-goverment. Bentuk penerapan e-goverment ini salah satunya adalah dengan penerapan e-audit. Dengan demikian e-audit merupakan key modernizing mechanism atau modernization bagi BPK RI, sejalan dengan Khan dan Chun dalam Kassen (2013: 52) bahwa e-goverment merupakan kunci modernisasi mekanisme pada organisasi kontemporer.

E-audit merupakan salah satu inovasi yang dilakukan oleh BPK RI dalam upaya pengembangan organisasinya. Hal tersebut seperti yang diungkapkan oleh Rogers (Darmawan, 2014: 28-29) bahwa "salah satu indikator masyarakat inovatif ditandai dengan upaya memanfaatkan perkembangan teknologi yang berkembang di dalam masyarakat." E-audit juga merupakan aktivitas pemerintahan melalui komunikasi elektronik khususnya dalam mengelola informasi seperti pendapat Fang (2002: 3)

Received: 20 Maret 2015, Revision:8 September 2015, Accepted: 31 Desember 2015

Print ISSN: 0215-8175; Online ISSN: 2303-2499. Copyright@2015. Published by Pusat Penerbitan Universitas (P2U) LPPM Unisba Terakreditasi SK Kemendikbud, No.040/P/2014, berlaku 18-02-2014 s.d 18-02-2019 
bahwa,

E-Government merupakan aktivitas pemerintah dalam menyediakan dan memperoleh data secara elektronis. Dengan E-Audit, BPK RI sebagai auditor akan terhubung dengan auditee melalui teknologi komunikasi dan informasi, sehingga sesuai dengan pendapat Nograsek (2011:14) bahwa E-Government sebaga penyatu antara berbagai unit pemerintahan.

Lebih lanjut lagi E-Audit juga memiliki beberapa elemen yang dimiliki E-Government yaitu sebagai modernisasi mekanisme, aktivitas elektronik, penghubung antarunit kerja, pengembangan organisasi, keterampilan teknologi informasi baru, peningkatan kualitas organisasi, serta pendorong reformasi organisasi publik. Dari lengkapnya elemen E-Audit tersebut diharapkan E-Audit mampu memberikan manfaat yang optimal. E-Audit sebagai E-Government dengan tipe G2G diharapkan mampu membantu tercapaianya pemeriksaan keuangan negara lebih akurat dan cepat, lebih luas, biaya lebih efisien, dan laporan pemeriksaan bisa terselesaikan dengan cepat (Praseno, 2012: 2).

Besarnya manfaat $E$-Audit ternyata juga dihadapkan oleh berbagai tantangan dalam pelaksanaannya. Seperti diketahui dari latar belakang pendidikan pemeriksa pada BPK RI Perwakilan Provinsi Sulawesi Tenggara yang sebagian besar adalah dari bidang studi akuntansi dan tidak ada satu pun yang memiliki latar belakang pendidikan teknologi informasi. Padahal, menurut Okab (2013: 181 ), salah satu tantangan penerapan $E$-Audit adalah kurangnya auditor yang juga memiliki spesialisasi dalam bidang teknologi informasi.

Dalam penerapan E-Audit, pemeriksa merupakan sumber daya yang memiliki peranan penting. Seperti yang disebutkan oleh Putera dkk (2011: 197-198) bahwa "Sumber daya menjadi mesin penggerak bagi bekerjanya sebuah program. Sumber daya menjadi energi bagi terlaksananya suatu program. Tanpa sumber daya yang mencukupi, mustahil program dapat dilaksanakan dengan baik. Lebih jauh lagi seperti yang dikatakan Nograsek (2011:22) bahwa E-Government tidak hanya sekadar isu teknologi, tetapi lebih ke isu perubahan organisasional. Oleh karena itu, dalam penerapan E-Audit tidak hanya dihadapkan pada masalah teknis tentang keterampilan dalam bidang teknologi informasi tetapi juga pada masalah reaksi terhadap perubahan karena penerapan E-Audit.

Berbagai tantangan tersebut yang menjadikan BPK RI harus benar-benar memiliki persiapan yang matang dalam penerapan E-Audit. E-Audit sebagai inovasi atau hal yang baru tentu saja memerlukan kesiapan yang tinggi. Hal tersebut sesuai dengan pendapat Park at al. (2014: 777) bahwa banyak terjadi kegagalan dalam pengembangan E-Government, oleh karena itu sangat penting untuk mengupayakan e-readiness sebelum mengembangkan E-Government tersebut.

Kesiapan/readiness yang dimaksud adalah tingkatan sejauh mana Pemeriksa sebagai sumber daya manusia pada BPK RI Perwakilan Provinsi Sulawesi Tenggara siap berpartisipasi dalam penerapan E-Audit. Beberapa ahli berpendapat bahwa kesiapan tersebut termasuk kesiapan sumber daya manusia atau yang biasa disebut people, human resource, atau user merupakan salah satu faktor pendukung e-readiness (McAdam \& Donaghy, 1999: 48; Goundinga \& Loub, 2013:268; Yaghoubi, 2011: 4; Mtwingi \& Belle, 2012: 63; Azab, 2009: 11).

Kesiapan Pemeriksa dalam penerapan E-Audit tersebut sangat berpengaruh terhadap keberhasilan penerapan E-Audit karena Pemeriksa merupakan core drivers of a business seperti yang juga diungkapkan oleh Loub (2013: 269) bahwa manusia merupakan inti penggerak suatu usaha. Namun selain itu, tidak dapat dipungkiri juga bahwa kesiapan pemeriksa tersebut dipengaruhi oleh karakteristik E-Audit sebagai inovasi seperti relative advantage, compatibility, ease of use, dan image. Oleh karena itu, dalam penelitian ini juga dilakukan analisis mengenai faktorfaktor yang berpengaruh terhadap kesiapan/ readiness tersebut.

Tulisan ini termasuk dalam penelitian sensus. Pemilihan metode penelitian ini dengan pertimbangan jumlah populasi yang sedikit (47 orang pemeriksa) dan bersifat heterogen (pangkat/golongan, peran, umur, tingkat pendidikan, dlI). Lokasi penelitian yang dipilih adalah BPK RI Perwakilan Provinsi Sulawesi Tenggara. Pengumpulan data dilakukan melalui dua upaya, yaitu melalui kuisioner dan dokumentasi. Variabel dalam penelitian ini adalah kesiapan/readiness $(Y)$ sebagai variabel dependen dan Relative advantage $\left(\mathrm{X}_{1}\right)$, compatibility $\left(\mathrm{X}_{2}\right)$, ease of use $\left(\mathrm{X}_{3}\right)$, dan image $\left(\mathrm{X}_{4}\right)$ sebagai variabel independen. Kemudian variabel-variabel tersebut dianalisis secara kuantitatif dengan metode regresi linear berganda.

Dari pendapat beberapa ahli dapat disimpulkan definisi konsep dari variabel- 
variabel penelitian ini. Relative advantage $\left(\mathrm{X}_{1}\right)$ adalah tingkat kelebihan atau keunggulan dari E-Audit bagi pemeriksa, compatibility $\left(\mathrm{X}_{2}\right)$ adalah tingkat kesesuaian E-Audit dalam proses pemeriksaan oleh pemeriksa, ease of use $\left(X_{3}\right)$ adalah tingkat kesulitan penggunaan $E$-Audit bagi pemeriksa, dan image $\left(\mathrm{X}_{4}\right)$ adalah citra atau reputasi pemeriksa setelah melakukan pemeriksaan dengan menggunakan inovasi E-Audit. Selanjutnya, dapat disimpulkan juga bahwa Kesiapan atau e-readiness adalah tingkatan sejauh mana pemeriksa sebagai sumber daya manusia pada BPK RI siap berpartisipasi dalam penerapan E-Audit.
Untuk mengukur variabel-variabel penelitian ditetapkan beberapa indikator masing-masing variabel. Indikator yang ditetapkan untuk variabel Relative advantage $\left(\mathrm{X}_{1}\right)$ yaitu untuk mengukur tingkat kelebihan atau keunggulan E-Audit sebagai sebuah inovasi antara lain sejauh mana E-Audit meningkatkan efisiensi kegiatan pemeriksaan, sejauh mana E-Audit meningkatkan efektivitas pelaksanaan kegiatan pemeriksaan, sejauh mana E-Audit membentuk pusat data pengelolaan dan tanggung jawab keuangan negara, dan sejauh mana E-Audit menerapkan konsep link and match data entitas pemeriksaan.

Tabel 1

Matriks Definisi Operasional

\begin{tabular}{lll}
\hline \multicolumn{1}{c}{ Variabel } & \multicolumn{1}{c}{ Dimensi } & \multicolumn{1}{c}{ Indikator } \\
\hline Relative advantage & Efektivitas, efisiensi, & 1. E-Audit meningkatkan efektivitas pemeriksaan \\
$\left(\mathrm{X}_{1}\right)$ & ekonomis, dan produktif & 2. E-Audit meningkatkan efisiensi pemeriksaan \\
& & 3. E-Audit meningkatkan ekonomis pemeriksaan \\
& & 4. E-Audit meningkatkan produktivitas pemeriksaan
\end{tabular}

\begin{tabular}{|c|c|c|}
\hline Variabel & Dimensi & Indikator \\
\hline & Pusat Data & $\begin{array}{l}\text { 5. E-Audit membentuk pusat data pengelolaan dan } \\
\text { tanggung jawab keuangan negara }\end{array}$ \\
\hline & Koneksi & $\begin{array}{l}\text { 6. E-Audit menerapkan konsep link and match data } \\
\text { entitas pemeriksaan }\end{array}$ \\
\hline \multirow[t]{2}{*}{ Compatibility $\left(\mathrm{X}_{2}\right)$} & $\begin{array}{l}\text { Kesesuaian dengan peme- } \\
\text { riksaan }\end{array}$ & 7. E-Audit sesuai tututan pemeriksaan \\
\hline & $\begin{array}{l}\text { Kesesuaian dengan peme- } \\
\text { riksa }\end{array}$ & $\begin{array}{l}\text { 8. E-Audit sesuai keinginan pemeriksa dalam proses } \\
\text { pengumpulan data dari auditee } \\
\text { 9. E-Audit sesuai keinginan pemeriksa dalam } \\
\text { berinteraksi dengan auditee } \\
\text { 10. E-Audit sesuai dengan budaya kerja pemeriksa }\end{array}$ \\
\hline Ease of use $\left(X_{3}\right)$ & $\begin{array}{l}\text { Kemudahan penggunaan } \\
\text { E-Audit bagi pemeriksa }\end{array}$ & $\begin{array}{l}\text { 11.E-Audit mudah dipelajari oleh pemeriksa } \\
\text { 12. Untuk terampil dalam menggunakan E-Audit } \\
\text { sangat mudah } \\
\text { 13. Tidak terdapat kendala dalam mempelajari } \\
\text { penggunaan E-Audit }\end{array}$ \\
\hline Image $\left(\mathrm{X}_{4}\right)$ & Reputasi pemeriksa & $\begin{array}{l}\text { 14. Menggunakan E-Audit membuat citra pemeriksa } \\
\text { lebih baik } \\
\text { 15. Menggunakan E-Audit membuat pemeriksa lebih } \\
\text { professional }\end{array}$ \\
\hline \multirow[t]{4}{*}{$\begin{array}{l}\text { Kesiapan/ } \\
\text { Readiness (Y) }\end{array}$} & 1. Kesadaran akan E-Audit & $\begin{array}{l}\text { 16.Pemeriksa telah memahami tentang E-Audit } \\
\text { 17.E-Audit telah disosialisasikan dengan baik }\end{array}$ \\
\hline & $\begin{array}{l}\text { 2. Pendidikan dan Pelatihan } \\
\text { tentang E-Audit }\end{array}$ & $\begin{array}{l}\text { 18.Pemeriksa telah dilatih sebagai pengguna } \\
\text { E-Audit } \\
\text { 19.Pendidikan dan Pelatihan mengenai E-Audit telah } \\
\text { cukup dilakukan }\end{array}$ \\
\hline & $\begin{array}{l}\text { 3. Kualifikasi dan pekerjaan } \\
\text { E-Audit }\end{array}$ & $\begin{array}{l}\text { 20.E-Audit sangat diperlukan dalam pemeriksaan } \\
\text { 21.Pemeriksa telah mampu mengaplikasikan } \\
\text { E-Audit }\end{array}$ \\
\hline & $\begin{array}{l}\text { 4. Kinerja dan kepuasan } \\
\text { akan E-Audit }\end{array}$ & $\begin{array}{l}\text { 22.E-Audit sangat membantu Pemeriksa } \\
\text { 23.E-Audit dapat terus digunakan dalam pemeriksaan }\end{array}$ \\
\hline
\end{tabular}

Sumber: diadaptasi dari teori Al-Osaimi (2007: 39), Rogers (Rokhman: 2011), Moore dan Benbasat (2004). 
Indikator untuk variabel compatibility $\left(\mathrm{X}_{2}\right)$, indikator yang digunakan adalah sejauh mana E-Audit sesuai keinginan pemeriksa dalam proses pengumpulan data dari auditee, sejauh mana E-Audit sesuai keinginan pemeriksa dalam berinteraksi dengan auditee, dan sejauh mana E-Audit sesuai dengan gaya hidup pemeriksa. Ease of use $\left(\mathrm{X}_{3}\right)$ menggunakan indikator sejauh mana E-Audit mudah dipelajari, sejauh mana dengan E-Audit proses perolehan data menjadi lebih jelas dan mudah dimengerti, sejauh mana $E$-Audit merupakan alat paling fleksibel untuk memperoleh data dari auditee dan sejauh mana kemudahan untuk terampil dalam menggunakan E-Audit. Kemudian variabel image $\left(\mathrm{X}_{4}\right)$ diukur dengan indikator sejauh mana penggunakan E-Audit membuat citra pemeriksa lebih baik dan sejauh mana penggunakan E-Audit membuat pemeriksa lebih profesional.

Selanjutnya, untuk variabel kesiapan atau e-readiness ( $Y$ ) sebagai variabel dependen menggunakan indikator sejauh mana Pemeriksa mengetahui tentang E-Audit, E-Audit telah disosialisasikan dengan baik, Pemeriksa telah dilatih sebagai pengguna E-Audit, kecukupan Pendidikan dan Pelatihan mengenai $E$-Audit, Proses pengumpulan data pemeriksaan memerlukan E-Audit, Perlu pelatihan khusus untuk penerapan E-Audit, E-Audit sangat membantu Pemeriksa, dan sejauh mana Pemeriksa puas atas penerapan E-Audit.

\section{Proses Pelaksanaan Pemeriksaan Tidak Terdapat perbedaan.}

BPK RI merupakan organisasi publik yang memiliki wewenang untuk memeriksa pengelolaan dan tanggung jawab tentang keuangan negara. Kantor pusat BPK RI berada di Jakarta Sebagai Ibukota negara. Sesuai dengan amanah Undang-Undang Dasar 1945, BPK RI memiliki perwakilan di setiap provinsi termasuk di Kendari, yaitu Pewakilan Provinsi Sulawesi Tenggara.

Dari Bezetting Pegawai BPK RI Perwakilan Provinsi Sulawesi Tenggara per 31 Juli 2014 dapat diketahui beberapa informasi kepegawaian. Jumlah pegawai adalah sebanyak 85 pegawai tetap (Pegawai Negeri Sipil dan Calon Pegawai Negeri Sipil) dan Pegawai Kontrak sebanyak 19 orang, sehingga total pegawai adalah sebanyak 104 pegawai.

BPK RI memunyai kewenangan untuk melakukan 3 (tiga) jenis pemeriksaan, yaitu
Pemeriksaan Keuangan, Pemeriksaan Kinerja, dan Pemeriksaan dengan Tujuan Tertentu. Meskipun pemeriksaan yang dilakukan oleh BPK RI dapat dikategorikan dalam tiga jenis pemeriksaan tetapi pada dasarnya proses pelaksanaan pemeriksaan tidak terdapat perbedaan. Hal tersebut dapat dilihat pada siklus pemeriksaan seperti pada Gambar 1.

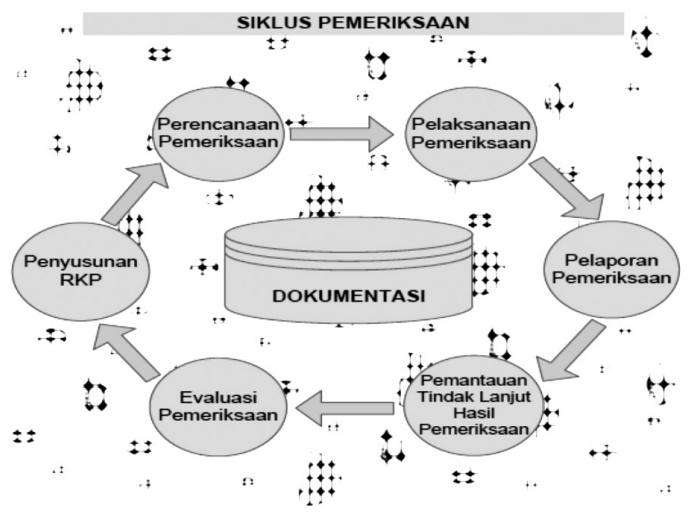

Gambar 1

Siklus Pemeriksaan (Surat Keputusan Sekretaris Jenderal BPK RI Nomor 245/K/X-XVIII.2/5/2012 tentang Grand Design E-Audit BPK)

Pemeriksaan merupakan corp business BPK RI oleh karena itu berbagai inovasi dilakukan dalam rangka mendukung tugas tersebut. Inovasi yang dilakukan dalam upaya mendukung proses pemeriksaan adalah E-Audit. E-Audit adalah sebuah sistem yang membentuk sinergi antara sistem informasi internal BPK (e-BPK) dengan sistem informasi milik entitas pemeriksaan (e-Auditee) melaluisebuah komunikasi data online antara e-BPK dengan e-Auditee dan membentuk PusatData pengelolaan dan tanggung jawab keuangan negara di BPK. Dengan demikian E-Audit merupakan pusat data yang dapat dimanfaatkan dalam proses pemeriksaan.

Sebagai langkah awal penerapan E-Audit, maka disusunlah Grand design E-Audit yang terealisasi dengan Surat Keputusan Sekretariat Jenderal BPK RI Nomor 245/K/X-XIII.2/5/2012 tentang Grand Design E-Audit BPK. Surat keputusan tersebut memuat berbagai hal mengenai penerapan E-Audit meliputi visi dan misi, tujuan, manfaat, dan gambaran penerapan E-Audit pada BPK RI.

Sebelum uji statistika dilakukan, terlebih dulu dilakukan uji validitas dan reliabilitas atas instrumen penelitian yang digunakan. 
Hal tersebut digunakan untuk membuktikan bahwa instrumen yang digunakan memiliki kesahihan dan keandalan instrumen penelitian. Uji validitas dan reliabilitas dilakukan dengan bantuan program SPSS 20. Uji validitas dilakukan dengan menggunakan teknik Korelasi Product Moment dan Alpha Cronbach untuk uji reliabilitas. Instrument berupa kuisioner yang digunakan terdiri dari 23 item pertanyaan yang dibagikan kepada 47 responden.

Variabel Relative Adventage (X1) terdiri enam item pertanyaan. Nilai koefisien korelasi terendah terdapat pada item pertanyaan ke-5 yaitu sebesar 0,481 dengan nilai signifikansi sebesar 0,001. Namun, nilai tersebut masih lebih besar dari nilai korelasi tabel sebesar 0,284 dan masih lebih kecil dari tingkat signifikansi sebesar 0,050. Dengan demikian dapat disimpulkan bahwa seluruh item pertanyaan pada variabel Relative Adventage $\left(X_{1}\right)$ ini valid.

Variabel Compatibility $\left(\mathrm{X}_{2}\right)$ terdiri atas empat item pertanyaan. Nilai koefisien korelasi terendah terdapat pada item pertanyaan ke 4 yaitu sebesar 0,650 . Namun demikian nilai tersebut masih lebih besar dari nilai korelasi tabel sebesar 0,284 sehingga disimpulkan bahwa seluruh item pertanyaan pada variabel Compatibility $\left(\mathrm{X}_{2}\right)$ ini valid.

Tabel 2

Pengujian Validitas Kuesioner "Relative Adventage" $\left(X_{1}\right)$

\begin{tabular}{l|ll|l|l|l}
\hline \multirow{2}{*}{ Pertanyaan } & \multicolumn{2}{|l|}{ Perhitungan } & \multicolumn{2}{l|}{ Pembanding } & \multirow{2}{*}{ Keterangan } \\
\cline { 2 - 5 } & $r_{\text {hitun }}$ & Signifikansi & $r_{\text {tabel }}$ & Signifikansi & \\
\hline 1 & 0,677 & 0,000 & 0,284 & 0,050 & Valid \\
2 & 0,830 & 0,000 & 0,284 & 0,050 & Valid \\
3 & 0,710 & 0,000 & 0,284 & 0,050 & Valid \\
4 & 0,791 & 0,000 & 0,284 & 0,050 & Valid \\
5 & 0,481 & 0,001 & 0,284 & 0,050 & Valid \\
6 & 0,517 & 0,000 & 0,284 & 0,050 & Valid \\
\hline
\end{tabular}

Tabel 3

Pengujian Validitas Kuesioner "Compatibility" $\left(\mathbf{X}_{2}\right)$

\begin{tabular}{|c|c|c|c|c|c|}
\hline \multirow{2}{*}{ Pertanyaan } & \multicolumn{2}{|c|}{ Perhitungan } & \multicolumn{2}{|c|}{ Pembanding } & \multirow{2}{*}{ Keterangan } \\
\hline & $\mathbf{r}_{\text {hitung }}$ & Signifikansi & $\mathbf{r}_{\text {tabel }}$ & Signifikansi & \\
\hline 1 & 0,708 & 0,000 & 0,284 & 0,050 & Valid \\
\hline 2 & 0,688 & 0,000 & 0,284 & 0,050 & Valid \\
\hline 3 & 0,791 & 0,000 & 0,284 & 0,050 & Valid \\
\hline 4 & 0,650 & 0,000 & 0,284 & 0,050 & Valid \\
\hline
\end{tabular}

Tabel 4

Pengujian Validitas Kuisioner Ease of Use $\left(\mathbf{X}_{3}\right)$

\begin{tabular}{llllll}
\hline Pertanyaan & Perhitungan & \multicolumn{3}{c}{ Pembanding } & Keterangan \\
& $r$ hitung & Signifikansi & $r$ tabel & Signifikansi & \\
\hline 1 & 0,877 & 0,000 & 0,284 & 0,050 & Valid \\
2 & 0,857 & 0,000 & 0,284 & 0,050 & Valid \\
3 & 0,892 & 0,000 & 0,284 & 0,050 & Valid \\
\hline
\end{tabular}

Tabel 5

Pengujian Validitas Kuesioner Image $\left(\mathbf{X}_{4}\right)$

\begin{tabular}{llllll}
\hline \multirow{2}{*}{ Pertanyaan } & \multicolumn{2}{l}{ Perhitungan } & \multicolumn{2}{l}{ Pembanding } & \multirow{2}{*}{ Keterangan } \\
\cline { 2 - 6 } & r hitung & Signifikansi & $r_{\text {tahel }}$ & Signifikansi & \\
\hline 1 & 0,922 & 0,000 & 0,284 & 0,050 & Valid \\
\hline 2 & 0,952 & 0,000 & 0,284 & 0,050 & Valid \\
\hline
\end{tabular}


Tabel 6

Pengujian Validitas Kuesioner Kesiapan/readiness ( $\mathbf{Y}$ )

\begin{tabular}{cccccc}
\hline Pertanyaan & \multicolumn{2}{c}{ Perhitungan } & \multicolumn{2}{c}{ Pembanding } & Keterangan \\
& r hitung & Signifikansi & r tabel & Signifikansi & \\
1 & 0,789 & 0,000 & 0,284 & 0,050 & Valid \\
2 & 0,849 & 0,000 & 0,284 & 0,050 & Valid \\
3 & 0,838 & 0,000 & 0,284 & 0,050 & Valid \\
4 & 0,836 & 0,000 & 0,284 & 0,050 & Valid \\
5 & 0,698 & 0,000 & 0,284 & 0,050 & Valid \\
6 & 0,835 & 0,000 & 0,284 & 0,050 & Valid \\
7 & 0,703 & 0,000 & 0,284 & 0,050 & Valid \\
8 & 0,726 & 0,000 & 0,284 & 0,050 & Valid \\
\hline
\end{tabular}

Tabel 7

Pengujian Reliabilitas Variabel Penelitian

\begin{tabular}{l|c|c|c}
\hline \multicolumn{1}{c|}{ Variabel } & Koefisien alpha & Ketetapan Nunely & Keterangan \\
\hline Relative Advantage $(\mathrm{X} 1)$ & 0,765 & 0,600 & Andal \\
\hline Compatibility $(\mathrm{X} 2)$ & 0,672 & 0,600 & Andal \\
\hline Ease of Use $(\mathrm{X} 3)$ & 0,829 & 0,600 & Andal \\
\hline Image $(\mathrm{X} 4)$ & 0,850 & 0,600 & Andal \\
\hline Kesiapan/readiness $(\mathrm{Y})$ & 0,912 & 0,600 & Andal \\
\hline
\end{tabular}

Tabel 8

Uji Asumsi Klasik Multikolenieritas

\begin{tabular}{l|l|l}
\hline \multicolumn{1}{c|}{ Variabel } & \multicolumn{2}{c}{ VIF } \\
\hline Relative Advantage $(\mathrm{X} 1)$ & \multicolumn{1}{c}{ Perhitungan } & \multicolumn{1}{c}{ Pembanding } \\
\hline Compatibility $(\mathrm{X} 2)$ & 1,923 & 10,000 \\
\hline Ease of Use $(\mathrm{X} 3)$ & 1,657 & 10,000 \\
\hline Image $(\mathrm{X} 4)$ & 1,184 & 10,000 \\
\hline & 2,461 & 10,000 \\
\hline
\end{tabular}

Sumber: data primer diolah, 2014

Variabel Ease of Use $\left(\mathrm{X}_{3}\right)$ terdiri atas tiga item pertanyaan. Nilai koefisien korelasi terendah terdapat pada item pertanyaan ke 2 yaitu sebesar 0,857. Namun demikian nilai tersebut masih lebih besar dari nilai korelasi tabel sebesar 0,284 sehingga disimpulkan bahwa seluruh item pertanyaan pada variabel Ease of Use $\left(\mathrm{X}_{3}\right)$ ini valid.

Variabel Image $\left(\mathrm{X}_{4}\right)$ terdiri atas dua item pertanyaan. Nilai koefisien korelasi terendah terdapat pada item pertanyaan pertama yaitu sebesar 0,922. Namun, nilai tersebut masih lebih besar dari nilai korelasi tabel sebesar 0,284, sehingga disimpulkan bahwa seluruh item pertanyaan padavariabel Image $\left(\mathrm{X}_{4}\right)$ ini valid.

Variabel Kesiapan/readiness (Y) terdiri dari delapan item pertanyaan. Nilai koefisien korelasi terendah terdapat pada item pertanyaan ke-5 yaitu sebesar 0,698.
Namun, nilai tersebut masih lebih besar dari nilai korelasi tabel sebesar 0,284 sehingga disimpulkan bahwa seluruh item pertanyaan padavariabel Kesiapan/readiness (Y) ini valid.

Berdasarkan tabel pengujian validitas kuesioner dapat diketahui bahwa hasil uji reliabilitas semua variabel penelitian memiliki nilai koefisien alpha yang lebih besar dari nilai ketetapan, yaitu sebesar 0,600. Dengan demikian dapat disimpulkan bahwa semua item pertanyaan pada variabel penelitian andal.

Sebelum dilakukan analisis data dengan regresi linier berganda maka dilakukan uji asumsi klasik. Uji asumsi klasik ini merupakan prasyarat dalam penggunaan analisis data dengan regresi linier berganda. Uji asumsi klasik tersebut meliputi uji asumsi klasik multikolenieritas, uji asumsi klasik heteroskedastisitas, uji asumsi klasik 
normalitas, dan uji asumsi klasik autokorelasi.

Uji asumsi klasik multikolenieritas di atas menggunakan besaran tolerance (a) sebesar $10 \%$ sehingga VIF adalah sebesar 10. Dari hasil perhitungan menunjukkan bahwa masing-masing variabel bebas memiliki nilai VIF kurang dari 10 . Oleh karena itu, dapat disimpulkan bahwa antar variabel bebas tidak terjadi multikolenieritas.

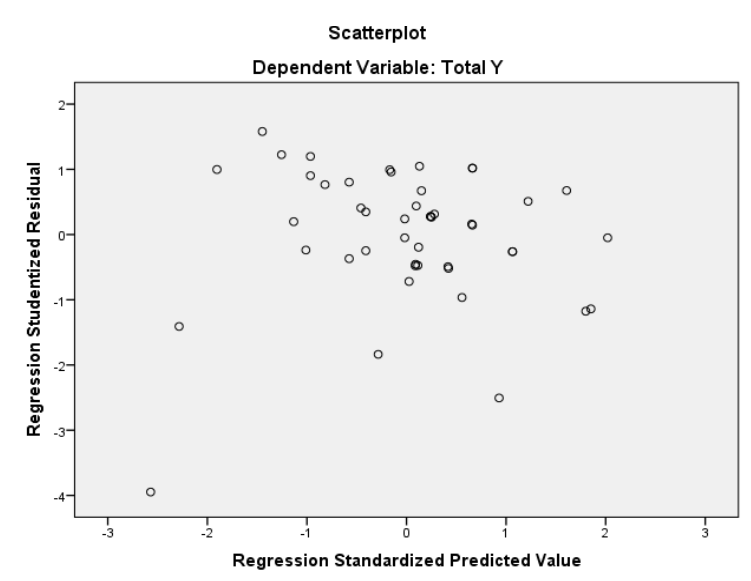

Gambar 2

Uji Asumsi Klasik Heteroskedastisitas

Dari hasil analisis dapat diperoleh gambar scatterplot di atas. Gambar tersebut menunjukkan bahwa terdapat titik-titik yang menyebar di bawah dan di atas sumbu $Y$ serta tidak mempunyai pola yang teratur. Oleh karena itu dapat disimpulkan bahwa antara variabel bebas tidak terjadi heteroskedastisitas atau bersifat homoskedastisitas.

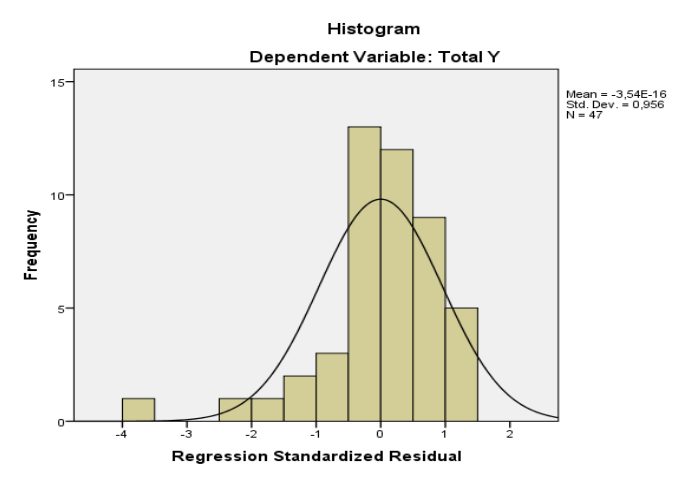

Gambar 3

Uji Asumsi Klasik Normalitas dengan Histogram

Dari gambar histogram di atas dapat diketahui bahwa garis kurva yang terbentuk merupakan garis kurva normal. Dengan demikian dapat diartikan bahwa data dalam penelitian ini berdistribusi normal. Selain dilihat dari gambar histogram di atas uji asumsi klasik normalitas juga dibuktikan dengan gambar normal probability plots.

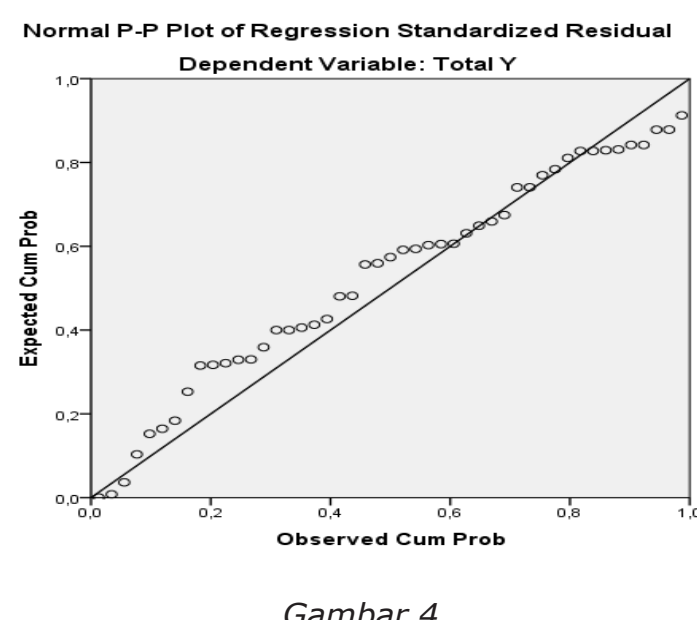

Uji Asumsi Klasik Normalitas dengan Normal Probability Plots

Sumber: data primer diolah, 2014)

Dari gambar Normal Probability Plots, dapat dilihat bahwa data berdistribusi normal. Hal tersebut dilihat dari garis (titik-titik) mengikuti garis diagonal. Dengan demikian, dari hasil histogram dan normal probability plots, maka dapat disimpulkan bahwa data dalam penelitian ini berdistribusi normal.

\section{Tabel 9}

Uji Asumsi Klasik Autokorelasi

\begin{tabular}{|c|l|l|}
\hline $\begin{array}{c}\text { Uji Asumsi Klasik } \\
\text { Autokorelasi }\end{array}$ & Durbin-Watson Test \\
\hline & Perhitungan & Pembanding \\
\hline $\begin{array}{c}\text { Durbin-Watson } \\
\text { Test }\end{array}$ & 2,277 & 2,000 \\
\hline
\end{tabular}

Sumber: data primer diolah, 2014

Hasil uji asumsi klasik autokerelasi dengan SPSS menunjukkan bahwa DurbinWatson Test adalah sebesar 2,277. Nilai tersebut jelas lebih besar dari nilai DurbinWatson Test yaitu sebesar 2 . Oleh karena itu dapat disimpulkan bahwa terjadi autokorelasi negatif pada data penelitian ini.

Berdasarkan data yang dikumpulkan dari 47 orang responden melalui kuesioner terdapat beberapa informasi yang dapat memberikan gambaran mengenai karakteristik responden. Informasi tersebut, antara lain menunjukkan sebaran responden berdasarkan 
jenis kelamin, umur, pendidikan terakhir dan jurusan, pangkat/golongan, peran, dan unit kerja. Sebagian besar responden berjenis kelamin laki-laki. Persentase responden dengan jenis kelamin laki-laki menjadi jenis kelamin mayoritas responden sebesar sebesar $80 \%$. Sedangkan responden dengan jenis kelamin perempuan hanya mencapai seperlima saja dari total responden atau sebesar $20 \%$.

Dengan mengaktegorisasikan usia responden menjadi tiga kategori sesuai kategorisasi usia menurut Departemen Kesehatan (Departemen Kesehatan: 2009), tabel di atas menunjukkan bahawa persentase tertinggi yaitu lebih dari 50\% responden, merupakan kelompok dewasa awal dengan rentang usia antara 26 sampai dengan 35 tahun. Selebihnya responden memiliki usia antara 36 sampai dengan 45 tahun (dewasa akhir) dengan persentase hampir $25,5 \%$ dan usia 46 sampai dengan 55 tahun dengan persentase $12,8 \%$. Hal tersebut menunjukkan bahwa semakin tua umur responden persentasenya semakin sedikit. Pendidikan responden didominasi oleh tingkat pendidikan S1 jurusan Akuntansi. Sisanya terdiri dari tingkat pendidikan DIII, DIV, S1 Non Akuntansi, dan S2.

Dapat diketahui juga bahwa dari seluruh responden tidak ada yang memiliki latar belakang pendidikan terakhir dari bidang teknologi informasi atau bidang lain sejenisnya. Komposisi responden dengan pangkat/golongan Penata (III/c) memiliki jumlah yang paling banyak yaitu sebesar 29,6\%. Selain pangkat/golongan Penata (III/c), pangkat/golongan Penata Muda Tingkat I (III/b) dan Penata Muda (III/a) juga memiliki prosentasi yang tidak jauh berbeda yaitu $27,7 \%$ dan $23,4 \%$. Sisanya terbagi dalam pangkat/golongan Pengatur (II/c), Pengatur Tingkat I (II/d), dan Pembina (IV/a).

Persentase terbanyak adalah responden dengan peran sebagai Anggota Tim Yunior. Persentase terbesar selanjutnya diikuti oleh peran Anggota Tim Senior, Ketua Tim Yunior, dan terakhir Ketua Tim Senior. Dengan demikian dapat disimpulkan bahwa semakin tinggi peran maka semakin sedikit persentase jumlah respondennya. Tidak terdapat perbedaan yang signifikan dalam komposisi responden berdasarkan unit kerja. Selisih jumlah responden hanya satu orang, sehingga persentase responden dari masingmasing unit kerja nyaris tidak berbeda.

Dari hasil penelitian dapat diketahui bahwa tingkat kesiapan/readiness Pemeriksa pada BPK RI Perawakilan Provinsi Sulawesi Tenggara dalam penerapan E-Audit dapat dikategorikan dalam kategori tinggi. Terlihat dari persentase kesiapan dalam kategori tinggi yang mencapai $48,9 \%$. Diikuti dengan tingkat kesiapan sedang sebesar 46,8\%. Sedangkan Pemeriksa dengan tingkat kesiapan rendah hanya sebesar $4,3 \%$.

Analisis kesiapan/readiness tersebut juga dapat dilihat berdasarkan jenis kelamin, umur, peran, dan unit kerja. Berdasarkan jenis kelamin, tingkat kesiapan/readiness tinggi berada pada Pemeriksa dengan jenis kelamin laki-laki dengan persentase sebesar $40,4 \%$. Berdasarkan usia kesiapan/readiness tinggi berada pada Pemeriksa dengan usia 26 sampai dengan 33 tahun dengan persentase sebesar $25,5 \%$. Berdasarkan peran, tingkat kesiapan/ readiness tinggi berada pada Pemeriksa dengan peran anggota tim yunior dengan persentase sebesar $19,1 \%$. Selanjutnya berdasarkan unit kerja, tingkat kesiapan/ readiness tinggi berada pada Pemeriksa dari Subauditorat Sultra II dengan persentase sebesar $29,8 \%$.

Proses penerapan E-Audit pada BPK RI Perwakilan Provinsi Sulawesi Tenggara tidak lepas dari proses difusi inovasi. E-Audit sebagai sebuah inovasi mengalami fase difusi yang meliputi komunikasi (Rogers, 1983:5) dan penyebaran (Zerika, 2013: 438) pada Pemeriksa sebagai user atau adopter. Sesuai pendapat Rogers (Liang, 2011: 132) yang membagi tipe berdasarkan tingkat adopsi maka Pemeriksa dapat digolongkan dalam tipe early adopters yang merupakan faktor penentu pengadopsian E-Audit. Proses difusi ini tentu saja dipengaruhi oleh beberapa karakteristik dari inovasi. Pada difusi E-Audit, karakteristik inovasi yang dipilh adalah relative advantage, compatibility, ease of use, dan image.

Keempat karakteristik tersebut kemudian dijadikan variabel penelitian. Hasil penelitian menunjukkan bahwa masingmasing variabel tersebut memiliki tingkatan yang cukup tinggi. Persentase masing-masing variabel relative advantage, compatibility, ease of use, dan image pada kategori tinggi yaitu $93,6 \%, 59,6 \%, 68,1 \%$, dan $74,5 \%$. Dengan demikian dapat disimpulkan bahwa E-Audit memiliki keunggulan atau kelebihan yang lebih tinggi dari pada sistem sebelumnya. E-Audit juga sesuai atau cocok dengan pemeriksaaan dan juga Pemeriksa. Kemudian E-Audit juga ternyata meningkatkan citra 
atau status Pemeriksa menjadi lebih baik. Selain itu E-Audit juga mudah digunakan oleh Pemeriksa.

Selanjutnya, keempat variabel di atas juga dikorelasikan dengan variabel kesiapan/ readiness dengan tingkat kesalahan 0,050 (5\%). Hasil analisisnya adalah bahwa masing-masing variabel relative advantage, compatibility, ease of use, dan image memiliki korelasi positif dengan variabel kesiapan/ readiness meskipun tingkat kekuatan hubungannya berbeda. Variabel relative advantage dan image memiliki korelasi yang sangat rendah terhadap kesiapan/readiness pemeriksa dalam penerapan itu E-Audit pada BPK RI Perwakilan Provinsi Sulawesi Tenggara dengan koefisien korelasi sebesar 0,080 dan 0,081. Variabel compatibility, memiliki korelasi yang rendah terhadap kesiapan/ readiness pemeriksa dalam penerapan itu E-Audit pada BPK RI Perwakilan Provinsi Sulawesi Tenggara dengan koefisien korelasi sebesar 0,322, sedangkan variabel ease of use memiliki korelasi yang kuat terhadap kesiapan/readiness pemeriksa dalam penerapan itu E-Audit pada BPK RI Perwakilan Provinsi Sulawesi Tenggara dengan koefisien korelasi sebesar 0,684. Namun demikian meskipun masing-masing variabel bebas tersebut memiliki korelasi positif ternyata hanya variabel compatibility dan ease of use yang signifikan.

\section{Tabel 10 \\ Korelasi Antar Variabel Bebas dengan Variabel Terikat}

\begin{tabular}{|l|l|l|}
\hline Variabel & Koefisien & $\begin{array}{c}\text { Tingkat Hubungan/ } \\
\text { Signifikansi }\end{array}$ \\
\hline Relative & 0,080 & $\begin{array}{l}\text { Sangat rendah } \\
\text { Tidak signifikan }\end{array}$ \\
\hline $\begin{array}{c}\text { Compatibility } \\
(\mathrm{X} 2)\end{array}$ & 0,322 & $\begin{array}{l}\text { Rendah } \\
\text { Signifikan }\end{array}$ \\
\hline $\begin{array}{c}\text { Ease of Use } \\
(\mathrm{X} 3)\end{array}$ & 0,684 & Kuat \\
Signifikan
\end{tabular}

Sumber: data primer diolah, 2014

Kemudian hasil analisis regresi berganda hanya mengikutsertakan variabel yang memiliki korelasi signifikan yaitu variable compatibility dan ease of use. Hasilnya diperoleh koefisien korelasi majemuk adalah sebesar 0,701 yang berarti bahwa secara bersama-sama variabel compatibility, dan ease of use memiliki hubungan korelasi yang kuat dengan variabel kesiapan/readiness pemeriksa dalam penerapan itu E-Audit pada BPK RI Perwakilan Provinsi Sulawesi Tenggara.

Tabel 11

\section{Korelasi Antar Variabel Secara Bersama-sama}

\begin{tabular}{|c|c|}
\hline & Koefisien \\
\hline $\begin{array}{l}\text { Korelasi variabel Compatibility } \\
\text { (X2) dan Ease of Use (X3) } \\
\text { terhadap variabel Kesiapan/ } \\
\text { readiness }(\mathrm{Y})\end{array}$ & 0,701 \\
\hline
\end{tabular}

Sumber: data primer diolah, 2014

Korelasi tersebut juga dikatakan signifikan karena dari tabel Anova dapat diketahui nilai $\mathrm{F}$ hitung adalah sebesar 21,309 dengan nilai $P$ atau Sig. sebesar 0,000 atau lebih rendah dari 0,050. Dengan demikian dapat disimpulkan bahwa terdapat korelasi bersama yang positif dan signifikan antara variabel Compatibility (X2) dan Ease of Use (X3) dengan variabel Kesiapan/readiness (Y).

Tabel 12

Signifikansi Regresi Antar Variabel

\begin{tabular}{|l|l|l|}
\hline & F & Sig. \\
\hline $\begin{array}{l}\text { Regresi Compatibility (X2) } \\
\text { dan Ease of Use (X3) terhadap } \\
\text { variabel Kesiapan/readiness } \\
\text { (Y) }\end{array}$ & 21,309 & 0,000 \\
\hline
\end{tabular}

Sumber: data primer diolah, 2014

Dari tabel di atas dapat diketahui bahwa koefisien korelasi berganda variabel Compatibility (X2) dan Ease of Use (X3) terhadap Kesiapan/readiness ( $Y$ ) sebesar 0,701 . Berarti kedua variabel Compatibility (X2) dan Ease of Use (X3) secara bersamasama mempunyai hubungan yang kuat dan positif. Koefisien determinan sebesar 0,492 atau 49,2\% artinya variabel Compatibility (X2) dan Ease of Use (X3) hanya dapat menjelaskan perubahan tingkat Kesiapan/ readiness $(Y)$ sebesar $49,2 \%$. Selain itu, dari uji $F$, diperoleh $F$ hitung sebesar 21,309 dan signifikansi sebesar 0,000 atau 0\%, lebih kecil dari alpha sebesar 5\%. Oleh karena itu, hubungan dapat disimpulkan adanya hubungan yang kuat positif dan signifikan.

Tabel 13 Koefisien Regresi

\begin{tabular}{|l|l|l|}
\hline & B & Sig. \\
\hline Konstanta & 8,922 & 0,193 \\
\hline
\end{tabular}




\begin{tabular}{|l|l|l|}
\hline Compatibility (X2) & 0,499 & 0,228 \\
\hline Ease of Use (X3) & 1,832 & 0,000 \\
\hline
\end{tabular}

Sumber: data primer diolah, 2014

Dari tabel di atas dapat diketahui bahwa koefisien korelasi berganda variabel Compatibility (X2) dan Ease of Use (X3) terhadap Kesiapan/readiness $(Y)$ sebesar 0,701 . Berarti kedua variabel Compatibility (X2) dan Ease of Use (X3) secara bersamasama mempunyai hubungan yang kuat dan positif. Koefisien determinan sebesar 0,492 atau $49,2 \%$ artinya variabel Compatibility (X2) dan Ease of Use (X3) hanya dapat menjelaskan perubahan tingkat Kesiapan/ readiness $(Y)$ sebesar $49,2 \%$. Selain itu dari uji $F$, diperoleh $F$ hitung sebesar 21,309 dan signifikansi sebesar 0,000 atau $0 \%$, lebih kecil dari alpha sebesar 5\%. Oleh karena itu, hubungan dapat disimpulkan adanya hubungan yang kuat positif dan signifikan.

Selanjutnya, untuk memperoleh hasil analisis yang lebih tajam maka masingmasing dimensi dari masing-masing variabel compatibility, dan ease of use dikorelasikan. Hasilnya menunjukkan bahwa dimensi kesesuaian E-Audit dengan pemeriksa dan kemudahan penggunaan $E$-Audit berpengaruh terhadap dimensi-dimensi kesiapan (readiness) dalam penerapan E-Audit.

\section{Simpulan dan Saran}

Dari hasil pembahasan dapat diketahui bahwa tingkat kesiapan/readiness pemeriksa pada BPK RI Perwakilan Provinsi Sulawesi Tenggara dalam penerapan E-Audit dapat dikategorikan dalam kategori tinggi, terlihat dari persentase kesiapan dalam kategori tinggi sebagai persentase terbesar dibandingkan dengan persentase kesiapan dalam kategori sedang dan rendah.

Pemeriksa dengan kesiapan dalam kategori tinggi tersebut sebagian besar berjenis kelamin laki-laki. Hal tersebut terjadi karena pemeriksa dengan jenis kelamin laki-laki mendominasi sumber daya pemeriksa pada pada BPK RI Perwakilan Provinsi Sulawesi Tenggara. Berdasarkan usia, Pemeriksa dengan kesiapan dalam kategori tinggi tersebut sebagian besar berusia antara 26 sampai dengan 35 tahun serta dengan peran sebagai Anggota Tim Yunior. Selain itu, Pemeriksa dari Subauditorat Sultra II memiliki persentase yang lebih besar dalam kelompok pemeriksa dengan kategori tinggi tersebut.

Selanjutnya, dari hasil pembahasan juga diketahui bahwa Compatibility dan Ease of Use memiliki pengaruh terhadap kesiapan/ readiness Pemeriksa pada BPK RI Perwakilan Provinsi Sulawesi Tenggara dalam penerapan E-Audit. Compatibility E-Audit pada BPK RI Perawakilan Provinsi Sulawesi Tenggara memiliki tingkatan yang tinggi. Namun demikian pengaruh Compatibility E-Audit terhadap kesiapan Pemeriksa pada BPK RI Perwakilan Provinsi Sulawesi Tenggara dalam penerapan E-Audit relatif kecil karena tingkat hubungan keduanya rendah. Ease of Use E-Audit sendiri juga memiliki tingkatan yang tinggi. Sama halnya dengan Compatibility E-Audit, Ease of Use E-Audit juga berpengaruh terhadap kesiapan Pemeriksa pada BPK RI Perwakilan Provinsi Sulawesi Tenggara dalam penerapan E-Audit. Namun, pengaruh Ease of Use E-Audit lebih besar karena tingkat hubungan Ease of Use dengan kesiapan/

Tabel 14

Korelasi Antar Dimensi

\begin{tabular}{|c|c|c|c|c|}
\hline \multirow[b]{2}{*}{$\begin{array}{c}\text { Dimensi } \\
\text { Compatibility } \\
\text { (X2), dan Ease of } \\
\text { Use (X3) }\end{array}$} & \multicolumn{4}{|c|}{ Dimensi Kesiapan / Readiness (Y) } \\
\hline & $\begin{array}{l}\text { Kesadaran } \\
\text { akan E-Audit }\end{array}$ & $\begin{array}{c}\text { Pendidikan dan } \\
\text { Pelatihan tentang } \\
\text { E-Audit }\end{array}$ & $\begin{array}{c}\text { Kualifikasi } \\
\text { dan Pekerjaan } \\
\text { E-Audit }\end{array}$ & $\begin{array}{c}\text { Kinerja dan } \\
\text { Kepuasan ana } \\
\text { E-Audit }\end{array}$ \\
\hline $\begin{array}{c}\text { Kesesuaian dengan } \\
\text { pemeriksaan }\end{array}$ & $\begin{array}{l}-0,130 / \\
\text { Tidak signifikan }\end{array}$ & $\begin{array}{l}-0,026 / \\
\text { Tidak signifikan }\end{array}$ & $\begin{array}{l}0,136 / \\
\text { Tidak signifikan }\end{array}$ & $\begin{array}{l}\text { 0,299/ } \\
\text { Tidak signifikan }\end{array}$ \\
\hline $\begin{array}{c}\text { Kesesuaian dengan } \\
\text { pemeriksa }\end{array}$ & $\begin{array}{l}\text { 0,361/ } \\
\text { Signifikan }\end{array}$ & $\begin{array}{l}0,325 / \\
\text { Signifikan }\end{array}$ & $\begin{array}{l}\text { 0,371/ } \\
\text { Signifikan }\end{array}$ & $\begin{array}{l}0,280 / \\
\text { Tidak signifikan }\end{array}$ \\
\hline $\begin{array}{c}\text { Kemudahan } \\
\text { penggunaan } \\
\text { E-Audit bagi } \\
\text { pemeriksa }\end{array}$ & $\begin{array}{l}0,703 / \\
\text { Signifikan }\end{array}$ & $\begin{array}{l}0,729 / \\
\text { Signifikan }\end{array}$ & 0,552/ signifikan & $\begin{array}{l}0,352 / \\
\text { Signifikan }\end{array}$ \\
\hline
\end{tabular}


readiness tersebut lebih kuat.

Kemudian, secara bersama-sama compatibility dan ease of use E-Audit memiliki pengaruh yang besar terhadap kesiapan Pemeriksa pada BPK RI Perwakilan Provinsi Sulawesi Tenggara dalam penerapan E-Audit. Compatibility dan ease of use E-Audit ini terdiri dari beberapa dimensi yang membentunya. Namun demikian dimensi kesesuaian E-Audit dengan Pemeriksa dan kemudahan penggunaan E-Audit menjadi dimensi yang paling berpengaruh besar terhadap kesiapan/readiness tersebut.

Pada akhirnya dapat disimpulkan bahwa Pemeriksa pada BPK RI Perwakilan Provinsi Sulawesi Tenggara siap terhadap penerapan E-Audit dengan tingkat kesiapan yang tinggi. Kesiapan tersebut dipengaruhi oleh faktor tingkat compatibility dan ease of use dari E-Audit. Analisis lebih mendalam lagi menunjukkan bahwa kesiapan/readiness dalam penerapan E-Audit dipengaruhi faktor kesesuaian E-Audit dengan pemeriksa dan kemudahan penggunaan E-Audit.

Hasil penelitian kesiapan/readiness Pemeriksa pada BPK RI Perawakilan Provinsi Sulawesi Tenggara terhadap penerapan E-Audit ternyata memberika hasil yang tidak jauh berbeda dengan hasil penelitian sejenis sebelumnya yang dilakukan pada BPK RI Perwakilan Provinsi Banten. Namun demikian, kedua hasil penelitian tersebut tidak bisa dijadikan dasar untuk mengeneralisasi bahwa Pemeriksa BPK RI secara keseluruhan telah siap terhadap penerapan E-Audit. Oleh karena itu perlu penelitian lebih lanjut mengenai kesiapan/readiness Pemeriksa pada BPK RI terhadap penerapan E-Audit pada Kantor perwakilan lain atau BPK RI secara keseluruhan.

Dari kesimpulan di atas maka dapat dirumuskan saran dalam penerapan E-Audit pada BPK RI Perwakilan Provinsi Sulawesi Tenggara. Untuk kesiapan/readiness Pemeriksa pada BPK RI Perawakilan Provinsi Sulawesi Tenggara terhadap penerapan E-Audit meskipun sudah dapat dikategorikan dalam kategori tinggi, namun tetap dipertahankan atau bahkan perlu untuk ditingkatkan. Hal tersebut menjadi sangat urgent karena berdasarkan jadwal rencana implementasi E-Audit diterapkan secara penuh pada tahun 2015.

Compatibility dari E-Audit memiliki tingkatan yang tinggi. Namun demikian karena Compatibility dari E-Audit ini memiliki pengaruh yang signifikan terhadap kesiapan/ readiness Pemeriksa pada BPK RI Perawakilan Provinsi Sulawesi Tenggara dalam penerapan E-Audit maka perlu dipertahankan atau bahkan ditingkatkan. Peningkatan Compatibility dari E-Audit sebaiknya terus dilakukan dengan menyesuaikan E-Audit dengan tuntutan Pemeriksa dan juga dengan kebutuhan pemeriksaan yang semakin kompleks.

Seperti halnya Compatibility dari E-Audit, Ease of use dari E-Audit meskipun memiliki tingkatan yang tinggi namun tetap perlu dipertahankan atau bahkan ditingkatkan. Hal tersebut karena Ease of use dari E-Audit juga memiliki pengaruh yang signifikan terhadap kesiapan/readiness Pemeriksa pada BPK RI Perawakilan Provinsi Sulawesi Tenggara dalam penerapan E-Audit. Peningkatan Ease of use dari E-Audit sebaiknya terus dilakukan dengan mengintensifkan pelatihan tentang penggunaan E-Audit kepada Pemeriksa.

Pelatihan tentang penggunaan E-Audit yang selama ini cenderung dilakukan hanya melalui pemberian pemahaman-pemahaman mengenai penggunaan E-Audit dengan sosialisasi bisa dikembangkan dengan pelatihan pemanfaatan inovasi $E$-Audit melalui simulasi pemeriksaan dengan menggunakan inovasi E-Audit. Dengan simulasi tersebut maka Pemeriksa tidak hanya bisa memahami penggunaan E-Audit tetapi juga mampu menguasai penggunaan E-Audit pada suatu pemeriksaan.

Intinya, dalam upaya untuk dapat meningkatkan tingkat kesiapan/readiness Pemeriksa pada BPK RI Perawakilan Provinsi Sulawesi Tenggara dalam penerapan E-Audit, perlu upaya lebih untuk meningkatkan tingkat Compatibility dan Ease of Use dari E-Audit. Dengan peningkatan Compatibility dan Ease of Use dari E-Audit, diharapkan kesiapan/readiness Pemeriksa pada BPK RI Perawakilan Provinsi Sulawesi Tenggara dalam penerapan E-Audit yang akan secara penuh diimplementasikan pada tahun 2015 nanti dapat lebih maksimal, sehingga pada akhirnya penerapan E-Audit sebagai salah satu bentuk implementasi E-Government pada BPK RI BPK RI Perawakilan Provinsi Sulawesi Tenggara dapat mencapai kesuksesan.

\section{Daftar Pustaka}

Azab, Nahed Amin, Sherif Kamel, and Georgios Dafoulas. (2009). A Suggested Framework for Assessing Electronic Government Readiness in Egypt. Electronic Journal of e-Government Volume 7 Issue 1, pp. $11-28$.

Darmawan, Deni. (2014). Peningkatan Aksesibilitas "3 M-Mobile Learning" sebagai Layanan Pendidikan. MIMBAR, 
Vol. 30, No. 1 (Juni, 2014): 28-41.

Fang, Zhiyuan. (2002). E-Government in Digital Era: Concept, Practice, and Development. International Journal of the Computer, the Internet and Management, Vol. 10, No.2, p 1-22.

Kassen, Maxat. (2013). Globalization of E-government: Open Government as a Global Agenda; Benefits, Limitations and Ways Forward. Information Development 2014, Vol. 30 (1) 51-58.

Latif, Abdul. (2012). Penilaian E-Audit Reasiness dengan Pendekatan Framework STOPE pada Badan Pemeriksa Keuangan (BPK) RI Perwakilan Provinsi Banten. Tesis. Fakultas Teknik, Universitas Gadjah Mada, Yogyakarta. (Tidak dipublikasikan).

Liang, Te-Hsin. (2011). The Awareness and Want Matrix with Adoption Gap Ratio Analysis for e-Service Diffusion Effect. Cyberpsychology, Behavior, and Social Networking Vol. 14, No. 3.

McAdam, Rodney and John Donaghy. (1999). Business process re-engineering in the public sector a study of staff perceptions and critical success factors. Business Process Management Journal, Vol. 5 No. 1, p. 49.

Nograsek. (2011). Change Management as a Critical Success Factor in e-Government Implementation. Business Systems Research, Vol. 2 No. 2, p.p 1-56.
Okab, Reem. (2013). Electronic Audit Role in Achieving Competitive Advantages and Support the Strategy of the External Audit in Auditing Offices in the Hashemite Kingdom of Jordan. International Business Research; Vol. 6, No. 6; p.p. 181-195.

Park, Sangin, Yeon-Tae Choi and Hong-Seok Bok. (2013). Does better e-readiness induce more use of e-government? Evidence from the Korean central e-government. International Review of Administrative Sciences 79(4) 767-789.

Praseno, Arief. (2012). IT-Based Audit (e-Audit) Plan in Indonesia: An Analysis of the Program Logic, Feasibility, and Alternatives. International Institute of Social Studies, The Hague, The Netherlands (Tidak dipublikasikan).

Putera, Roni Ekha dan Tengku Rika Valentina. 2014. Implementasi Program KTP Elektronik (e-KTP) di Daerah Percontohan. MIMBAR, Vol. XXVII, No. 2 (Desember 2011): 193-201.

Rogers, Everett M. 1983. Diffusion of Innovations Third Edition. The Free Press: New York.

Yaghoubi, Nour-Mohammad, Saeed fallah tafti, dan Mahmood hazrati. 2011. E-readiness Measurement through Fuzzy Analytical Hierarchy Process (FAHP) Case Study: Tehran Stock Exchange. Australian Journal of Basic and Applied Sciences, 5(3): 436441. 